\title{
PENDIDIKAN OKULTISME DALAM MEMPERLENGKAPI JEMAAT UNTUK BERIMAN KEPADA ALLAH DI GKSI “JEMAAT ELOHIM” KALIMANTAN TENGAH
}

\author{
Dr. Jonidius Illu' ${ }^{1}$, Elia Boen Eni \\ Sekolah Tinggi Teologi Injili Arastamar (SETIA) Jakarta \\ joni.illu@gmail.com
}

\begin{abstract}
Abstrak
Isu-isu pokok yang dibahas tentang beberapa hal, diantaranya adanya kalangan orang Kristen yang tidak meyakini akan keberadaan Setan yang berdampak pada tidak ada kepekaan terhadap kehadiran dan cara kerja Setan, namun disisi lain juga ada orang Kristen merasa takut yang berlebihan terhadap berbagai tipu muslihat Setan dan tidak memahami bagaimana menghadapi atau mengusir kuasa Setan, pada akhirnya memiliki ketergantungan kepada pendeta atau hamba Tuhan karena dianggap berkompeten untuk pengusiran Setan.

Tujuan penelitian untuk menunjukkan kepada orang Kristen bahwa kuasa Setan sekarang statusnya sudah dikalahkan melalui kematian dan kebangkitan Kristus dan kuasa Setan tidak dapat mengalahkan orang yang telah percaya dan beriman kepada Yesus Kristus sebagai Tuhan dan Juruselamat.

Metode yang digunakan adalah penelitian kualitatif dengan harapan dapat meyakinkan setiap orang percaya agar mengetahui dan meyakini akan statusnya di dalam Kristus (Kol. 2:9-10).

Kata kuncinya: Kematian dan kebangkitan Kristus, kuasa Okultisme sudah dikalahkan.
\end{abstract}

\section{Abstract}

The main issues discussed on a number of things, including the existence of Christians who do not believe in the existence of Satan that results in no sensitivity to the presence and workings of Satan, but on the other hand there are also Christians who feel excessive fear of Satan's deception. and not understanding how to deal with or drive out the power of Satan, ultimately has a dependency on priests or servants of God because they are considered competent for the expulsion of Satan.

The purpose of the research is to show Christians that the power of Satan is now defeated through the death and resurrection of Christ and that the power of Satan cannot defeat those who have believed and believed in Jesus Christ as Lord and Savior.

The method used is qualitative research in the hope of convincing every believer to know and believe in his status in Christ (Col. 2: 9-10).

The key word: Christ's death and resurrection, the power of the Occult has been defeated.

\section{PENDAHULUAN}

Pendidikan okultisme sebagai bagian dari cara untuk memperlengkapi jemaat untuk mengetahui tentang keberadaan okultisme, asal-usul, posisi sekarang dan akhir dari keberadaan okultisme.

Alkitab menjelaskan keberadaan okultisme yang berusaha merusak kehidupan iman jemaat, di sisi lain Alkitab juga menjelaskan bahwa okultisme tidak memiliki kekuatan karena kuasa Kristus dan otoritas yang diberikan Nya kepada orang beriman.

Dalam tulisan ini, penulis memaparkan pentingnya pendidikan okultisme guna memperlengkapi jemaat agar menyadari bahwa kuasa okultisme sedang bekerja untuk merusak kehidupan orang beriman dan karenanya jemaat perlu diperlengkapi agar tidak salah menyikapi atau menghadapi okultisme.

\footnotetext{
${ }^{1}$ Dosen Tetap Sekolah Tinggi Teologi Injili Arastamar (SETIA) Jakarta

${ }^{2}$ Mahasiswa Magister Teologi Sekolah Tinggi Teologi Injili Arastamar (SETIA) Jakarta
} 
GKSI “Jemaat Elohim” Kalimantan Tengah, dimulai pada April 2019. Jemaat tersebut, banyak yang memiliki latarbelakang kepercayaan penyembahan berhala, spiritisme, tahayul. Hal ini menyebabkan ketakutan, dan karenanya melakukan ritual-ritual untuk menghadapinya ${ }^{3}$. Kehadiran GKSI memiliki dampak yang signifikan dimana jemaat-jemaat yang mau menerima Yesus secara pribadi diajarkan Firman Tuhan secara berulang-ulang dengan metode pendalaman Alkitab ${ }^{4}$. Pengalaman penulis yang beberapa kali mengunjungi jemaat tersebut melihat ada perubahan cara berpikir dan berprilaku, salah satunya adalah banyak jemaat yang tidak lagi mengalami ketakutan terhadap kuasa Setan dan tidak lagi melakukan penyembahan berhala.

\section{METODE PELAKSANAAN}

$\begin{array}{ll}\text { Waktu } & : \text { 26-29 April } 2019 \\ \text { Tempat } & : \text { GKSI “Jemaat Elohim” Kalimantan Tengah } \\ \text { Alat yang digunakan : Alkitab dan Materi Pembinaan }\end{array}$

\section{HASIL DAN PEMBAHASAN}

A. Pendidikan okultisme

Pendidikan okultisme penting karena orang banyak memiliki pemahaman yang keliru tentang okultisme, akibatnya perasaan takut yang luar biasa.

Akitab menjelaskan bahwa sejak pemberontakan Malaikat Lucifer bersama sepertiga malaikat telah dibuang ke bumi sehingga statusnya bukan lagi sebagai pelayan Allah melainkan sebagai pemberontak atau penentang Allah (Yes. 14:12-17 dan Yeh. 28:11-19). ${ }^{5}$ Selain itu ketakutan yang luar biasa orang Kristen terhadap berbagai cara kerja okultisme. ${ }^{6}$ Untuk itu pendidikan okultisme penting karena beberapa alasan:

1. Pendidikan okultisme berguna dalam memberikan wawasan tentang semua cara kerja okultisme yang sudah terjadi dan yang sekarang terjadi dan bagaimana sikap orang percaya terhadap cara kerja tersebut.

2. Pendidikan okultisme penting untuk persiapan dalam menetapkan prinsip-prinsip iman Kristen yang sesuai dengan Alkitab dalam menghadapi kuasa Setan agar tidak ditakutkan atau diintimidasi. Contoh ketika Yesus dicobai di Padang Gurun (Mat. 4:1-11). Dalam cerita ini dapat dilihat bahwa Yesus sendiri dicobai oleh Setan sebanyak tiga kali dengan tiga macam pencobaan yang berbeda antara lain: kebutuhan jasmani Yesus sebagai manusia (Yesus lapar), jika Yesus mau silahkan menjatuhkan diri ke bawah, dengan syarat Yesus harus menyembahnya. Yesus dengan tegas dan berkata manusia hanya boleh menyembah dan berbakti kepada Allah. ${ }^{7}$

3. Pendidikan okultisme berupaya menjelaskan dan memperlengkapi dengan konsep dan strategi yang tepat dalam mendomonstrasikan kuasa Yesus Kristus terhadap manusia

\footnotetext{
${ }^{3}$ Berdasarkan hasil pengamatan dan diskusi dengan beberapa Hamba Tuhan dan pelayan jemaat, diantaranya Pak Ilo (penatua) pada tanggal 3 Desember 2018.

${ }^{4}$ Hasil wawancara dengan Pdt. Elia Bon Eni (Ketua BPW - GKSI) Kalimantan Tengah pada tanggal 4 Desember 2019.

${ }^{5}$ Kedua bacaan tersebut menjelaskan bahwa Setan benar ada, dan ini terjadi karena sebagai ciptaan Allah yang dutugaskan untuk melayani Allah justru karena kecongkakannya ingin merebut takhta Allah sebagai akibatnya ia dibuang ke bumi. Lihat editor Dianne dan Robert J. Karris, Tafsiran Alkitab Perjanjian Lama (Yogyakarta: Kanisius, 2002), 525, 604-605.

${ }^{6}$ Pandangan ini keliru karena berdasarkan 1 Petrus 5:8, Setan siap menyerang orang Kristen kapan saja untuk melakukan keinginannya sehingga perlu siap siaga. Setan bagaikan binatang buas yang sangat berbahaya, berkeliaran di mana saja yang membuat dunia tidak aman. Selain itu, sebagai musuh yang tidak dapat direka-reka tindakannya dan melintasi seluruh dunia (Ayb. 1:7; 2:2). Lihat buku P. H. R. Van Houwelingen, Surat 1 Petrus (Surabaya: Momentum, 2018), 316- 320.
}

${ }^{7}$ Lihat Leon Moris, Tafsiran Injil Matius (Surabaya: Momentum, 2016), 73-83. 
yang terikat dan menderita akibat okultisme, sehingga orang Kristen meyakini bahwa kuasa Yesus Kristus dan status orang percaya tidak dapat dikalahkan oleh kuasa Setan.

4. Pendidikan okultisme menjelaskan tentang keabsahan akan kehadiran okultisme dalam dunia dan manusia adalah sasarannya. Oleh karena itu, sebagai orang yang percaya Yesus Kristus perlu memiliki strategi dalam menghadapi okultisme.

5. Pendidikan okultisme ini menggumuli akan keikutsertaan orang Kristen dalam menghadirkan kuasa Kristus atas dunia yang sudah dikuasai okultisme. ${ }^{8}$

B. Okultisme

1. Pengertian Okultisme

Okultisme adalah ilmu yang mempelajari tentang hal-hal yang supranatural atau teori tentang hal-hal yang terjadi diluar nalar pikiran manusia. Berikut ini beberapa contoh: a) ada orang yang sedang kemasukan roh jahat ketika dipotong dengan parang tidak terluka; b) ada orang yang sedang kerasukan kemudian meminta makanan dan orang tersebut makan sampai berpiring piring, diluar kemampuan daya tampung normal tetapi masih merasa lapar; c) membaca mantra kemudian terbang dari satu tempat ke tempat lain tanpa menggunakan pesawat.

2. Bentuk-bentuk okultisme

Beberapa bentuk okultisme yang masih diyakini bahkan mengikat dan mengintimidasi manusia antara lain:

a. Takhayul.

Artinya keyakinan pada apa perkataan atau kepercayaan yang tidak memiliki dasar yang pasti tetapi dapat diyakini dan menakutkan. Pada dasarnya takhayul selalu membuat manusia hidup dalam ketakutan bila melanggar keyakinan tak beralasan itu, misalnya jika diganggu Setan maka bisa diusir dengan menggunakan darah babi dengan cara darah babi dipercikan keliling rumah, contoh lain, jika malam jumat maka tidak boleh keluar rumah karena banyak Setan yang berjalan dan dapat membunuh manusia.

b. Meramal nasib

Adalah tindakan dimana seseorang diramalkan masa dengan menggunakan sarana yang ada, seperti diramalkan masa depannya dengan melihat telapak tangan, dengan menggunakan kartu, dengan melihat tanggal lahir atau bulan lahir, dan dengan melihat bintang. Peramal atau penenung tidak mengklaim bahwa mereka menyodorkan kemungkinan. Karena itu, peramal menggunakan berbagai macam tanda (omen) dan menyerahkan keputusan final kepada orang yang mencari nasihatnya. ${ }^{9}$

c. Spiritisme

Ada keyakinan atau kepercayaan bahwa orang yang sudah meninggal masih memiliki hubungan dengan yang masih hidup. Itu sebabnya bagi yang masih hidup melakukan ritual-ritual seperti memberikan makanan pada roh orang yang sudah meninggal, bermimpi bahwa yang meninggal itu datang dan berbicara sesuatu agar dilakukan misalnya diantara keluarga ada yang sakit dan bermimpi bahwa ia sakit karena tidak membersihkan kuburan, sebagai tanggapan terhadap mimpi tersebut maka ia kemudian membersihkan kuburan, dan lain-lain.

3. Alasan orang Kristen tidak boleh terikat atau diperbudak okultisme

Tujuan Allah menciptakan manusia agar memuliakan nama-Nya, namun manusia dengan status sebagai orang berdosa selalu tergoda untuk mengikuti keinginan $\operatorname{Setan}^{10}$, misalnya ada tawaran supaya menjadi kaya, naik jabatan atau dihormati maka ke tempat

\footnotetext{
${ }^{8}$ Lihat J. C. Ryle, Aspek-aspek Kekudusan (Surabaya: Momentum, 2003), 33-38.

${ }^{9}$ Willem A. VanGemeren, Penginterpretasian Kitab Para Nabi (Surabaya: Momentum, 2016), 10.

${ }^{10}$ Setan memiliki berbagai strategi untuk menggoda manusia. Setan berusaha agar manusian tertarik dengan dosa dan kemudian melakukan dosa. Lihat Stephen Tong, Roh Kudus, Suara Hati Nurani dan Setan (Surabaya: Momentum, 2011), 97.
} 
tertentu dan mengikuti ritual, akibatnya karena membuka hati untuk keinginan tersebut berdampak terjadi keterikatan dengan okultisme. Perlu diingat bahwa Alkitab dengan jelas mengatakan dalam 1 Petrus 5:8 berkata, "Iblis seperti singa yang mengaum mencari mangsa." Sebagai orang Kristen perlu mengingat beberapa hal yang berkaitan dengan pekerjaan Setan, antara lain:

a. Setan berusaha untuk membunuh dan membinasakan (Yoh. 10:10b). Setan ingin membunuh kita karena tubuh kita adalah bait Allah (1 Kor. 6:19, 20), alat Allah (Rm. 6:12,13), dan harta Allah yang berharga (2 Kor. 4:7).

b. Setan itu pendusta. Cerita dalam Kejadian 3 bahwa Setan telah mendustai Adam dan Hawa dengan berkata, jika memakan buah pohon yang berada di tengah taman tidak akan mati tetapi akan seperti Tuhan yang mahatahu segalanya. Adam dan Hawa mengikutinya sehingga akibatnya mereka mati.

c. Setan itu penguasa. Dalam dunia ini, ada dua kekuatan yang sedang bekerja yaitu kekuatan Tuhan dan kekuatan Setan. Setan selalu berusaha sehingga manusia mengikuti keinginannya dan takut kepadanya. Dijelaskan oleh Paul Enns ${ }^{11}$ bahwa, "Kristus mengambil tempat manusia, dan melalui kematian substitusionari-Nya, Ia mengalahkan Setan, menyatakan bahwa ia tak berdaya dalam kehidupan orang percaya. Setan memiliki kuasa kematian atas orang, tetapi kuasa itu dipatahkan oleh Kristus (Ibr. 2:14). Dalam Yohanes 5:19 berkata bahwa dunia ini berada dalam kuasa Setan dan Yesus pun mengakui itu (Yoh. 12:31; 16:11). John Piper ${ }^{12}$ berkata,

"Mereka belum binasa. Kita masih bergumul dengan mereka sampai saat ini. Tetapi mereka merupakan musuh yang telah kalah. Kita tahu bahwa kemenangan sudah menjadi milik kita. Ini seperti seekor naga yang kepalanya dipotong dan dibiarkan berdarah sampai mati. Perang sudah dimenangkan. Tetapi kita masih terus berhati-hati terhadap kerusakan yang masih bisa dilakukannya."

d. Setan itu mendakwa. Orang yang sudah percaya Yesus Kristus tidak akan mengalami dakwaan Setan, tetapi sebaliknya orang yang belum percaya Yesus Kristus akan didakwa sehingga terus-menerus melakukan keinginannya.

e. Setan itu penggoda. Setan berusaha akan memakai kelemahan dalam diri orang percaya untuk menggodanya, misalnya kelemahan dalam hal marah maka Setan berusaha menjatuhkan dengan memakai hal tersebut. Selain itu, Setan berusaha agar kita menyesuaikan diri dengan keadaan yang berkembang sekarang atau tatanan dunia yang bertentangan dengan Firman Tuhan, agar jatuh dalam hal asusila (1 Kor. 7:5) dan hal-hal yang lain.

4. Akibat keterlibatan dalam okultisme

Tuhan sebagai pribadi yang diagungkan dan dimuliakan, itu sebabnya Tuhan membenci dan memberikan hukuman kepada manusia yang menduakan-Nya. Dalam Keluaran 20:3-6, Tuhan melarang manusia menyembah ilah lain dan membuat patung menyerupai apa pun untuk disembah, sehingga manusia yang melakukan hal ini akan mendapat hukuman dari Tuhan.

C. Beriman kepada Allah

1. Otoritas kematian dan kebangkitan Kristus. Kematian dan kebangkitan Kristus telah mengalahkan tiga hal yaitu kuasa dosa, kuasa maut dan kuasa Setan (bdk. Rm. 8:37-39). Oleh karena itu, sebagai orang yang beriman kepada Yesus Krisus tidak boleh takut menghadapi atau ditakuti kuasa Setan karena pada prinsipnya Setan yang sedang bekerja dengan segala kuasanya sudah dikalahkan. ${ }^{13}$

\footnotetext{
${ }^{11}$ Paul Enns, Buku Pegangan Teologi (Malang: SAAT, 2003), 363.

${ }^{12}$ John Piper, Penderitaan Kristus (Surabaya: Momentum, 2010), 92-93.

${ }^{13}$ Jan A. Boersema, dkk., Berteologi Abad XXI (Jakarta: Perkantas, 2015), 403.
} 
2. Status orang percaya. Orang yang percaya Yesus Kristus memiliki status yang istimewa karena disebut sebagai anak-anak Allah (Yoh. 1:12) yang pada awalnya diperbudak oleh kuasa kegelapan (kuasa Setan - Kol. 1:13) dan setelah dibebaskan maka Roh Kudus berdiam dalam hidup orang percaya (Ef. 1:13) untuk semakin membenci dosa dan hidup dalam kesucian. ${ }^{14}$ Dalam status demikian maka tidak akan diperbudak oleh kuasa Setan melainkan akan menunjukkan hidup yang berkenan kepada Tuhan dan tidak takut jika diperhadapkan dengan kuasa Setan. Ditegaskan oleh Armand Barus bahwa,

"Allah telah melepaskan jemaat Kolose dari kuasa kegelapan yang dikuasai roh jahat dan setan (Luk. 22:53; Kis. 26:18). Manusia apa pun kelompak etnisnya, berada di bawah kerajaan kegelapan. Manusia tidak mampu melepaskan dirinya. Tidak ada kuasa dalam dirinya untuk melawan penguasa kegelapan. Namun, Allah telah melepaskan jemaat dari kuasa Setan. Pelepasan ini tidak berarti jemaat telah sepenuhnya lepas dari pengaruh penguasa kegelapan. Jemaat belum sepenuhnya berada di surga, masih berada di dunia. ${ }^{15}$

3. Jaminan perlindungan

Yesus Kristus menjamin perlindungan bagi orang yang percaya. berikut ini beberapa bagian Firman Tuhan yang menjelaskannya antara lain:

a. Kolose 2:9-10, "Sebab dalam Dialah berdiam secara jasmaniah seluruh kepenuhan ke-Allahan, dan kamu telah dipenuhi di dalam Dia. Dialah kepala semua pemerintah dan penguasa. Yesus adalah Allah dan juga manusia sejati yang berkuasa menjaga orang percaya dari kuasa Setan sehingga tidak perlu takut. ${ }^{16}$

b. Kolose 3:3-4, "Sebab kamu telah mati dan hidupmu tersembunyi bersama dengan Kristus di dalam Allah. Apabila Kristus, yang adalah hidup kita, menyatakan diri kelak, kamu pun akan menyatakan diri bersama dengan Dia dalam kemuliaan. Artinya hidup orang Kristen tersembunyi di dalam Kristus sehingga pasti aman dan tidak dapat disentuh siapa pun serta keamanan ini terjamin dalam kekekalan. ${ }^{17}$

c. 1 Yohanes 4:4b, "sebab Roh yang ada di dalam kamu, lebih besar dari pada roh yang ada di dalam dunia." Orang yang sudah percaya hidupnya ada Roh Kudus (Ef. 1:13), sehingga dalam menghadapi kuasa Setan tidak akan mungkin Setan menang melawannya.

D. Pendidikan okultisme dalam memperlengkapi jemaat untuk beriman kepada Allah

1. Mengajarkan Firman Tuhan. Roma 10:17 berkata, "Jadi, iman timbul dari pendengaran, dan pendengaran oleh firman Kristus. Artinya jemaat diajarkan Firman Tuhan secara berulang-ulang agar semakin dikuatkan oleh pengajaran Firman Tuhan.

2. Selalu mencari Tuhan. Ada ketekunan dari jemaat sebagai respon atas keselamatan.

3. Memberikan pemahaman tentang okultisme berdasarkan Alkitab.

4. Mengajarkan strategi dalam menghadapi okultisme, antara lain:

a. Diperlengkapan dengan senjata Allah (Ef. 6:11-12) agar tidak dapat dibohongi oleh okultisme.

b. Beriman. Keyakinan bahwa kuasa okultisme sudah dikalahkan melalui kematian dan kebangkitan Yesus Kristus (Rm. 8:27-29; Kol. 2:9-10).

\footnotetext{
${ }^{14}$ Paulus memberitahukan kepada kita untuk meninggalkan manusia lama dan mengenakan manusia baru agar melalui ketaatan sehingga semakin menyerupai Kristus (Ef. 4:22-32) dan natur yang baru semakin menjadi pola hidup kita. Petrus mengatakan, kita menyucikan diri dengan menaati kebenaran, karena Allah telah melahirbarukan kita dengan Firman-Nya sebagai benih yang mencerminkan natur-Nya (1 Ptr. 1:22-25; bdk. Luk. 8:11; Yak. 1:21; 1 Yoh. 3:9). Lihat Craig S. Keener, Mengenali dan Mengalami Kuasa Roh Kudus (Jakarta: Perkantas, 2015 ), 93.

${ }^{15}$ Armand Barus, Surat Kolose - Tafsiran Alkitab Kontekstual - Oikumenis (Jakarta: BPK. Gunung Mulia, 2018), 112.

${ }^{16}$ lihatArmand Barus, Surat Kolose - Tafsiran Alkitab Kontekstual - Oikumenis, 281-285.

${ }^{17}$ lihatArmand Barus, Surat Kolose - Tafsiran Alkitab Kontekstual-Oikumenis, 358-364.
} 
c. Firman. Prilaku yang tidak bertentangan dengan Firman Allah. Alkitab memberi perintah untuk ditaati, janji-janji untuk dituntut dan prinsip-prinsip untuk diikuti. Hal ini merupakan bagian dari ketaatan terhadap Firman Allah. ${ }^{18}$

d. Doa. Salah satu cara pengusiran okultisme dengan doa. Artinya pengusiran okultisme menjadi berhasil karena doa dilakukan dalam menyebut nama Yesus (Mat. 17:21) dan otoritas orang Kristen yang berdoa (Yak. 4:7)

e. Berjalan di dalam Roh (Gal. 5:22-26). Artinya orang yang sudah diselamatkan di dalam Yesus Kristus telah menyalibkan semua keinginan daging dan hidup dalam pimpinan Roh Kudus sehingga semua aspek hidupnya bukan lagi menyenangkan Setan tetapi mempermuliakan Yesus Kristus. ${ }^{19}$ Sebab jika ada peluang orang Kristen melakukan dosa, maka hal tersebut menjadi cela masuknya Setan merusak kehidupan Kristen tetapi sebaliknya hidup dalam pimpinan Roh Kudus atau berjalan di kekudusan maka Setan pun takut untuk mengganggu.

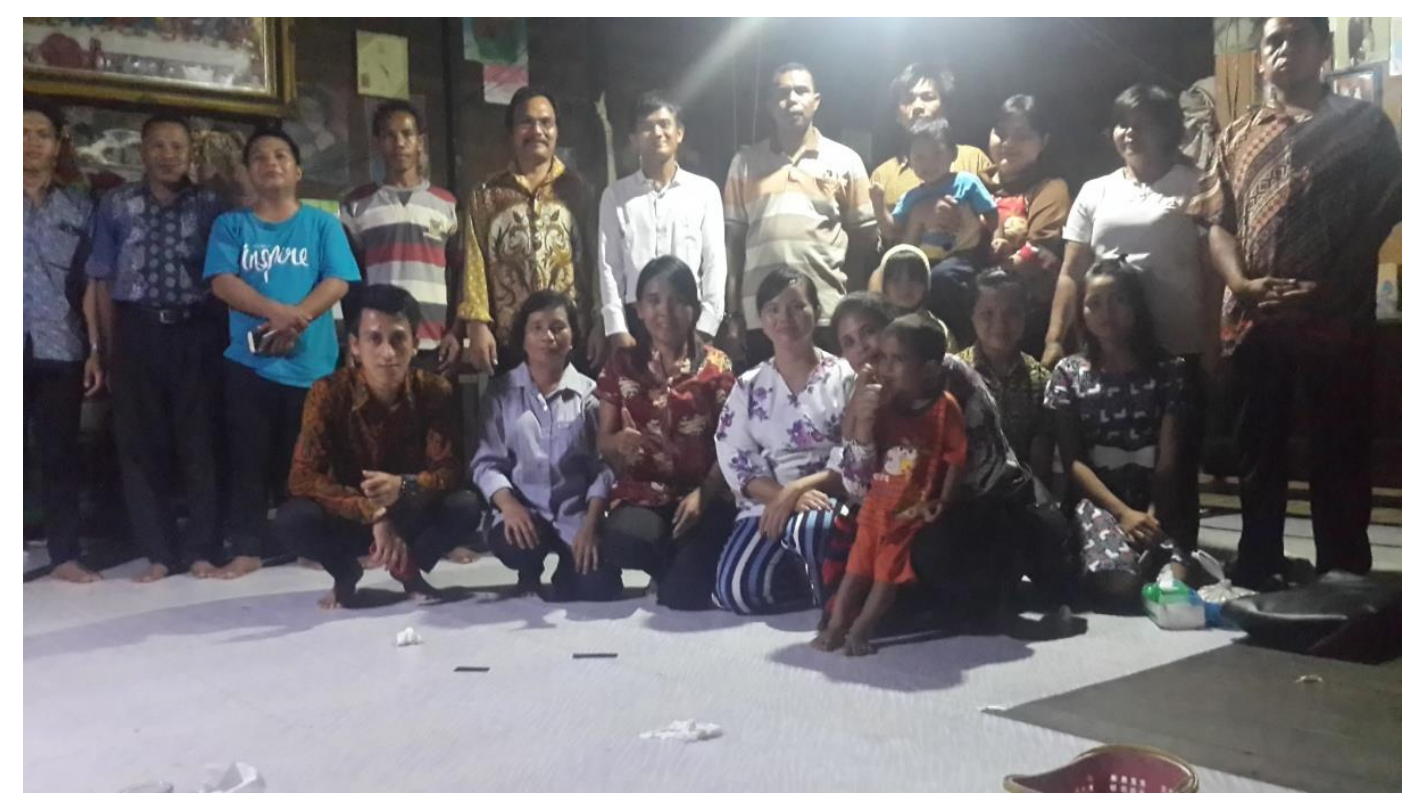

\section{KESIMPULAN}

Berikut ini beberapa kesimpulan antara lain:

1. Mengajarkan okultisme berguna dalam memberikan pemahaman yang benar sesuai Alkitab sehingga jemaat tidak lagi terlibat dalam okultisme.

2. Jemaat dapat membedakan budaya mana yang bertentangan dengan Firman Allah dan tidak boleh lagi dilakukan.

3. Jemaat dapat membimbing keluarga yang masih terlibat okultisme untuk meninggalkanya.

\section{DAFTAR PUSTAKA}

Barus, Armand. Surat Kolose - Tafsiran Alkitab Kontekstual - Oikumenis. Jakarta: BPK. Gunung Mulia. 2018.

Boersema, Jan A. dkk., Berteologi Abad XXI. Jakarta: Perkantas. 2015.

Enns, Paul. Buku Pegangan Teologi. Malang: SAAT. 2003.

Karris, Dianne dan Robert J. Tafsiran Alkitab Perjanjian Lama. Yogyakarta: Kanisius. 2002.

Keener, Craig S. Mengenali dan Mengalami Kuasa Roh Kudus. Jakarta: Perkantas. 2015.

Moris, Leon. Tafsiran Injil Matius. Surabaya: Momentum. 2016.

Piper, John. Penderitaan Kristus. Surabaya: Momentum. 2010.

Ryle, J. C. Aspek-aspek Kekudusan. Surabaya: Momentum. 2003.

\footnotetext{
${ }^{18}$ Warren W. Wiersbe, Strategi Setan (Yogyakarta: ANDI, 2007), 119.

${ }^{19}$ Agus Santoso, Tafsiran Surat Rasul Paulus Kepada Jemaat di Galatia (Bandung: BMI, 2011), 140-141.
} 
Tong, Stephen. Roh Kudus, Suara Hati Nurani dan Setan. Surabaya: Momentum. 2011. Van Houwelingen. P. H. R., Surat 1 Petrus. Surabaya: Momentum. 2018.

VanGemeren, Willem A. Penginterpretasian Kitab Para Nabi. Surabaya: Momentum. 2016. Wiersbe, Warren W. Strategi Setan. Yogyakarta: ANDI. 2007.

Santoso, Agus. Tafsiran Surat Rasul Paulus Kepada Jemaat di Galatia. Bandung: BMI. 2011. 